\title{
Regional and Local Mineral Dust Characterisation over South America
}

\author{
DAMIAN OYARZUN ${ }^{1,2,3}$, NICOLAS HUNEEUS ${ }^{1,3}$ AND \\ MARIEL OPAZO $^{1,3}$ \\ ${ }^{1}$ Universidad de Chile \\ ${ }^{2}$ University College London \\ ${ }^{3}$ Center for Climate and Resilience Research (CR)2 \\ Presenting Author: damian.oyarzun@uchile.cl
}

The overall production of mineral dust in South America has been estimated to be about $2.3-2.6 \%$ of the global production. Whereas most of the studies have historically been focused on Asia and the Sahara Desert, South America has received scarce attention, especially on local sources characterisation. The above, despite its potential for solar power generation[2].

A satellite-based analysis was conducted to describe mineral dust sources at both regional and local scales. The regional analysis was based on MODIS Deep Blue products of Aerosol Optical Depth (AOD) and Angstrom Exponent () between 2015 and 2019. The local-scale characterisation was carried out using the MODIS MCD19A2 product, which employs the multi-angle MAIAC algorithm for retrieving AOD at $1 \mathrm{~km}$ resolution. High values of AOD along with low values of were associated with mineral dust sources. A sensitivity test for $<1.0,<0.6$ and $<0.3$ was performed. The above approach was also contrasted with Dust Optical Depth (DOD) estimations as formulated by Anderson[1].

No significant differences were found between the AOD-AE and DOD methods. Along with minor sources scattered over West-Northern Argentina, the two major mineral dust sources were identified in the Atacama Desert and the Argentinian Patagonia. These exhibit a distinctive seasonal cycle with higher AOD in summertime accompanied by a wide range of values (0.0-1.4). This suggests multiple sources with a dominant presence of mineral dust. On the contrary, wintertime is characterised by lower AOD and high values ( $>1.0)$, suggesting fine-particles dominance, such as those from anthropogenic pollution. In addition to the above, the occurrence of dust events for both identified dust sources was studied, In particular, the Atacama Desert presents a high frequency of mid-intensity dust outbreaks, over 20 in summer with area-averaged AOD $>0.5$ and $<1.0$. These results and the occurrence of exceptional dust outbreaks are discussed in terms of their implications for solar energy production, air quality, and modelling validation applications.

[1] Anderson, T. L., et al.(2005). Testing the MODIS satellite retrieval of aerosol fine-mode fraction. JGeophysicRes:Atmospheres,110(D18).

[2] Rondanelli, R., et al.(2015). The Atacama surface solar maximum. Bulletin American MetSociety,96(3),405-418. 